\title{
Radiochemical Research with Transactinide Elements in Switzerland
}

\author{
Patrick Steinegger ${ }^{\star}$ and Robert Eichler
}

\begin{abstract}
Here, we present a review on a fundamental radiochemical research topic performed by Swiss scientists in national and international collaborations, utilizing large accelerator facilities at the Paul Scherrer Institute as well as abroad. The chemical investigation of the heaviest elements of the periodic table is a truly multidisciplinary effort, which allows scientists to venture into a variety of fields ranging from nuclear and radiochemistry to experimental and theoretical work in inorganic and physical chemistry all the way to nuclear and atomic physics. The structure and fundamental ordering scheme of all elements in the periodic table, as established more than 150 years ago, is at stake: The ever increasing addition of new elements at the heavy end of the periodic table together with a growing influence of relativistic effects, raises the question of how much periodicity applies in this region of the table. Research on the heaviest chemical elements requires access to large heavy-ion accelerator facilities as well as to rare actinide isotopes as target materials. Thus, this scientific area is inevitably embedded in joint international efforts. Its fundamental character ensures academic relevance and thereby substantially contributes to the future of nuclear sciences in Switzerland.
\end{abstract}

Keywords: Periodic table $\cdot$ Relativistic effects $\cdot$ Superheavy elements $\cdot$ Transactinide elements $\cdot$ Transactinides

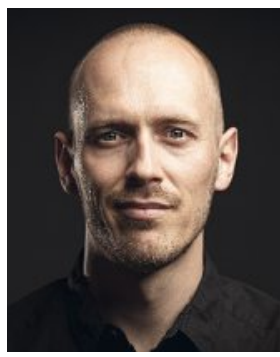

Dr. Patrick Steinegger studied chemistry at and obtained his $\mathrm{PhD}$ degree from the University of Bern (Prof. Dr. A. Türler). For his $\mathrm{PhD}$ thesis on vacuum chromatography of group 13 elements as a model study for element nihonium ( $\mathrm{Nh}, Z=113$ ), he was awarded the thesis prize of the GDCh (Gesellschaft Deutscher Chemiker) and the Eduard-Adolf-Stein-Prize of the Faculty of Philosophy and Natural Sciences of the University of Bern. Following his PhD, Dr. Steinegger spent almost four years at the Flerov Laboratory of Nuclear Reactions in Dubna, Russia, first as an SNSF fellow and later on as staff scientist. In 2019 he was appointed in tenure-track as group leader of the Heavy Elements group at the Laboratory of Radiochemistry of the Paul Scherrer Institute (PSI).

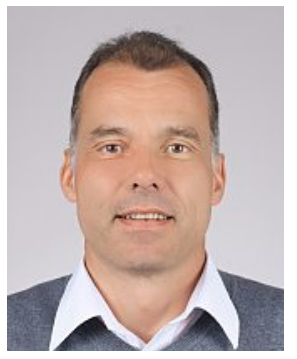

Dr. Robert Eichler studied chemistry in Dresden and Darmstadt and obtained his $\mathrm{PhD}$ degree from the University of Bern (Prof. Dr. H. W. Gäggeler) on the topic 'First chemical investigation of bohrium (element 107)', for which he was awarded with the GDCh thesis prize and the $\mathrm{PhD}$ prize of the University of Bern in the year 2000. After a post-doctoral position at the University of Mainz and the Gesellschaft für Schwerionenforschung in Darmstadt, he was appointed as group leader of the Heavy Elements group at PSI in 2002. In 2004, Dr. Eichler was granted a two-year SNSF fellowship to work at the Lawrence Berkeley National Laboratory, while still heading the group at PSI. As of 2017, he is acting head of the Laboratory of Radiochemistry at PSI.

\section{Introduction}

Amongst the various exciting research fields of radiochemistry, such as those presented in this volume, the chemical characterization of superheavy elements (SHEs) belongs to the most fundamental topics. Also referred to as transactinides (atomic number $Z \geq 104$ ), these elements represent the newest members of the periodic table of elements. This most important tool of chemical sciences was introduced in 1869 by Russian scientist D. I. Mendeleev ${ }^{[1,2]}$ and others, ${ }^{[3]}$ who devised an ordering scheme of the elements according to their atomic weights and chemical properties. Consequently, the established laws of periodicity were applied from the very beginning to predict chemical properties of known elements as well as to predict the existence of new, hitherto unknown elements. It was Mendeleev himself, who predicted, e.g. the natural existence of scandium, gallium, and germanium. ${ }^{[4]}$ Only recently, the seventh row of the periodic table was completed with the latest addition of four newly discovered, artificial elements up to oganesson $(\mathrm{Og}, Z=118) .{ }^{[5]}$ However, the placement of new elements into the periodic table raises questions on how much these new members fit the overall physicochemical behavior of the respective group. Whereas originally, the sorting of elements was based among others on their atomic weights, H. G. J. Moseley's early works in 1913/1914 justified instead an ordering of the elements according to their atomic number. ${ }^{[6]}$ Nonetheless, since the advent of quantum mechanics with works by E. Schrödinger in Zurich in 1926 and others, the explanation for the chemical ordering was finally established as being based on the electronic structure of the elements. ${ }^{[7]}$ These truly groundbreaking discoveries did not change Mendeleev's table dramatically, as the electronic structure of the elements is strongly connected to their chemical properties. In 1929, P. A. M. Dirac combined mathematically A. Einstein's special relativity ${ }^{[8]}$ (Bern in 1905) with the quantum mechanical description of electrons and postulated a negligible influence of relativity on chemical properties. ${ }^{[9]}$ It was not until 1979, that P. Pyykkö and J.-P. Desclaux demonstrated the importance of relativistic effects in chemistry in their seminal paper titled 'Relativity and the Periodic System of Elements'. ${ }^{[10]}$ Scaling roughly with the square of the atomic number $Z^{2}$, i.e. the nuclear charge, these 
effects become increasingly relevant for the description of the electronic structure of heavier elements and thus for predicting and understanding their physicochemical properties. In fact, relativistic effects are responsible for a number of anomalies in the latter half of the periodic table, e.g. the appearance and chemical behavior of gold, the liquid standard state of mercury, or the transition from a predominant oxidation state + III for the light group 13 elements to $\mathrm{a}+\mathrm{I}$ state for their heavy homolog thallium and presumably for nihonium $(\mathrm{Nh}, Z=113) .{ }^{[10]}$ Since then, chemical and physical theory have developed extensively to quantify those effects. However, the increasing number of electrons and their mutual correlation make ab initio calculations extremely challenging. Sophisticated, numerically approximating approaches have been established to circumvent these problems and are widely used nowadays to calculate chemical structure and bonding in all fields of chemistry (see ref. [11] for reviews).

In parallel, chemical experiments with the heaviest elements started in 1966 with pioneering works of Zvara and co-workers in Dubna, Russia with the investigation of the first SHE rutherfordium (Rf, $Z=104$ ). ${ }^{[12]}$ Since the very beginning, researchers of the University of Bern and of the Swiss Federal Institute for Reactor Research (EIR; merged in 1988 with the Swiss Institute for Nuclear Research, SIN, to form the Paul Scherrer Institute, PSI) were involved in this field of fundamental research. Firstly, the contributions focused on the search of primordial SHEs in nature based on most sensitive spontaneous fission (SF) measurements. ${ }^{[13]}$ Later on, the emphasis shifted to experimental studies targeting the physical and chemical characterization of SHEs obviously a prerequisite for finding these elements in nature. Despite on-going efforts, ${ }^{[14]}$ thus far, no evidence has been found for their existence in nature (for a recent review see ref. [15]). Therefore, the elements have had to be produced in heavy-ioninduced nuclear fusion evaporation reactions using high-intensity, high-energy heavy-ion beams from large accelerators (see ref. [16] for reviews). The achievable production rates using that most favorable approach range from single atoms per minute down to single atoms per month. All known isotopes of transactinide elements today mainly feature half-lives in the single-second to submillisecond regime. Rarely, and only recently, half-lives in the range of up to minutes and even hours were observed (see Fig. 1) among the $\alpha$-decay products of the heaviest SHEs leading to neutron-rich radioisotopes of lighter transactinides. After a successful period of first experiments with these newest members of the periodic table, chemical investigations started lagging behind the discovery of new elements. Therefore, further experimental facilities were needed, dedicating accelerator time to this kind of research. With the installation of an electron cyclotron resonance ion source (ECRIS) at the Injector 1 Phillips cyclotron at PSI in 1992, the acceleration of heavy ions and thus the production of SHEs in Switzerland became feasible. In the period following this installation, a large number of experiments with transactinides was conducted together with a variety of instrumental homolog studies in preparation of those demanding investigations. This investment bolstered the position of the Heavy Elements group at PSI as a leading entity in the field of SHE research with highly visible achievements (see Section 2). Particularly noteworthy is the development of highly sophisticated techniques for the gasphase chemical characterization of transactinide elements. PSI's strategy of installing the new large scale facility Swiss Spallation Neutron Source SINQ opened up new possibilities, particularly after the shut-down of the Philipps cyclotron in 2010: Driven by the world-leading, high-intensity proton accelerator complex (HIPA) with proton beam intensities of more than $2.5 \mathrm{~mA}$ at energies of $590 \mathrm{MeV}$, the SINQ has enabled the production of important radionuclides for radiochemical development work. Even though all experimental developments as well as the vast majority of tests are still done at PSI, the Swiss researchers of the Heavy Elements group have had to rely on fruitful collaborations with partner institutions abroad for their final experiments with transactinide elements ever since the decommissioning of the Injector 1 cyclotron. The international partner institutions in Russia, Germany, Japan, the USA, and China have provided the needed access to their heavy-ion accelerator facilities. Currently, new constructions and severe modernizations are about to be finished at many of these accelerator centers. These upgraded or even entirely new facilities will deliver heavy-ion beams of unprecedented intensities and provide electromagnetic separators (i.e. used to separate the produced SHEs from the primary ion beam and the plethora of nuclear reaction byproducts) offering highest transmission efficiencies. Such international commitments are interpreted as the dawn of a new era with unparalleled possibilities in transactinide research.

Herein, we review the chemical experiments performed on transactinide elements conducted under the lead of the Swiss group from PSI (as well as earlier from the University of Bern) and present a possible roadmap towards future Swiss activities in the field.

\section{Current State of Transactinide Research}

The current status in the field of transactinide research has been nicely reviewed in the past. ${ }^{[18]}$ The timeline for the discoveries and chemical investigations of SHEs is presented in Table 1. Up to the year 1992, only two transactinide elements, i.e. the later named elements rutherfordium and dubnium ( $\mathrm{Db}, Z=105)$, had been intensively studied chemically. This scarcity of results regarding the chemistry of SHEs was due to the lack of efficient enough production facilities for the synthesis of transactinides as well as suitable chemical investigation devices. Since these early experiments using liquid-phase chemical methods as well as gasphase adsorption separation techniques, the main intention has been the comparison of the chemical properties of single atoms of transactinide elements with the same properties of single atoms of their lighter homologs in identical chemical systems. Generally, such chemical investigations impose several demanding prerequisites: 1) The preservation of a defined chemical state throughout the experiment; 2) a highly repetitive way of establishing chemical equilibria with single atoms in chromatographic systems; 3 ) a high separation velocity, accounting for the short half-lives; 4) high efficiencies, accounting for the low production rates; and last but not least 5) the unambiguous identification of the single atoms. The latter point directly depends on the selected, high-level physical/chemical separation from interfering by-products from nuclear production processes.

Instrumental and usually most time-consuming are the preparatory steps taken before addressing a transactinide element in an accelerator-based chemistry experiment. Homolog studies at the so-called one-atom-at-a-time level are crucial for the later success with SHEs. The optimization of experimental efficiencies and the identification of a specific chemical species is a stringent requirement in this challenging endeavor. Therefore, a large part of the preparations is based on experiments with carrier-free radioisotopes of the homologs of the element in question (see ref. [18] for reviews). Therefore, such tracers need to be readily available in order to ensure the success of this field of research. Hereto, the Heavy Elements group at PSI is in a unique position, as it operates the neutron irradiation service NIS at SINQ, ${ }^{[19]}$ runs the SINQ-based fission product gas-jet facility, ${ }^{[20]}$ and uses the isotope production facilities at the $72-\mathrm{MeV}$-proton beam line of the Injector 2 cyclotron. ${ }^{[21]}$

Another crucial radiochemical aspect of SHE research is related to the targets irradiated by intense heavy-ion beams. Due to the limited scope of this article, the radiochemistry and material science behind the preparation of such targets is not discussed here. However, the required targets for transactinide research are made 


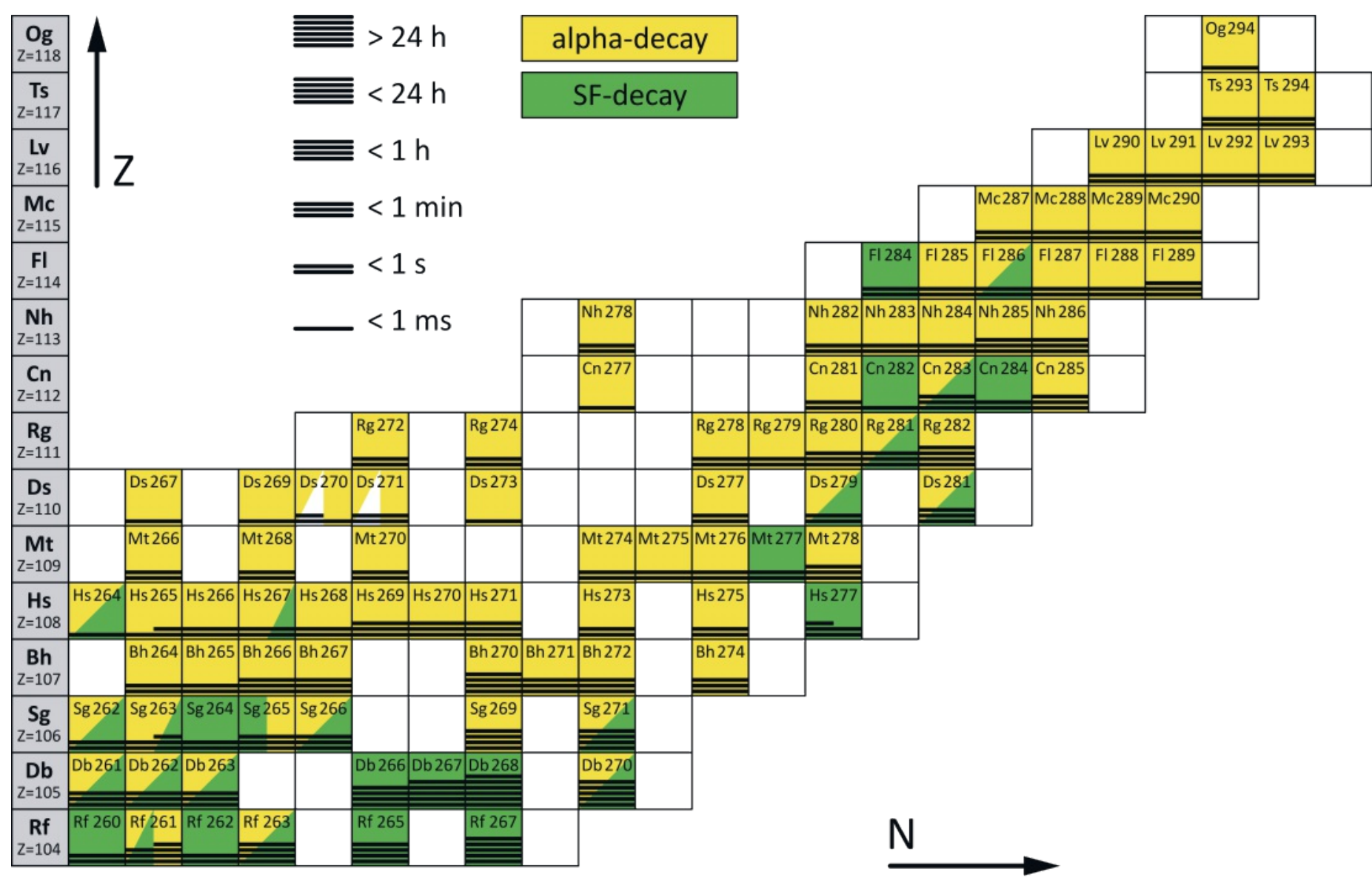

Fig. 1. Excerpt of the chart of nuclides in the region of SHEs with $N$ being the neutron number and $Z$ the atomic number; half-lives (black stripes) and predominant decay modes (colors) are indicated. The underlying data and color scheme was adopted from ref. [17].

Table 1. Time line of the discovery (i.e. first reported observation) and chemical identification of transactinide elements (for reviews see ref. [18]); whereas the chemical identification was instrumental for a successful claim of discovery in the onset of transactinide synthesis, purely nuclear-physics-based approaches have been prevailing ever since.

\begin{tabular}{|l|l|l|l|}
\hline $\begin{array}{l}\text { Transactinide } \\
\text { elements }\end{array}$ & $\begin{array}{l}\text { Atomic } \\
\text { number Z }\end{array}$ & Discovery & $\begin{array}{l}\mathbf{1}^{\text {st }} \text { chemical } \\
\text { identification }\end{array}$ \\
\hline Rutherfordium (Rf) & 104 & 1969 & 1969 \\
\hline Dubnium (Db) & 105 & 1970 & 1972 \\
\hline Seaborgium (Sg) & 106 & 1974 & 1997 \\
\hline Bohrium (Bh) & 107 & 1981 & 2000 \\
\hline Hassium (Hs) & 108 & 1984 & 2002 \\
\hline Meitnerium (Mt) & 109 & 1982 & - \\
\hline Darmstadtium (Ds) & 110 & 1994 & - \\
\hline Roentgenium (Rg) & 111 & 1994 & - \\
\hline Copernicium (Cn) & 112 & 1996 & 2007 \\
\hline Nihonium (Nh) & 113 & 2004 & 2014 \\
\hline Flerovium (Fl) & 114 & 1999 & 2010 \\
\hline Moscovium (Mc) & 115 & 2003 & - \\
\hline Livermorium (Lv) & 116 & 2000 & - \\
\hline Tennessine (Ts) & 117 & 2010 & - \\
\hline Oganesson (Og) & 118 & 2002 & - \\
\hline
\end{tabular}

out of rare isotopes typically produced in the High Flux Isotope Reactors of the Oak Ridge National Laboratory, Oak Ridge, Tennessee, USA as well as at the Research Institute of Atomic Reactors (RIAR) in Dimitrovgrad, Russia (see, e.g. ref. [16c] and references therein). The production includes even radioisotopes of heaviest actinides up to californium $(\mathrm{Cf}, Z=98)$ and einsteinium (Es, $Z=99$ ). Permanent improvements, such as provided by, e.g. Swiss radiochemistry, are required, in particular with the new high-intensity ion beam facilities emerging across the globe.[22]

\subsection{Transition Metals with d-Character}

For the transactinide elements of the transition metal series, the stabilization of the chemical state was pursued by choosing chemical systems where the SHE is in its highest oxidation state. These chemical compounds are presumed to be the most stable ones for the transition metal series as stabilities of higher oxidations states along the subgroups increase towards the heavier members of the periodic table, i.e. a presumption based on the laws of periodicity. Therefore, volatile gaseous, single-molecular halides and oxohalides of $\mathrm{Rf}(\mathrm{IV})$ and $\mathrm{Db}(\mathrm{v})$ as well as their metalcomplex siblings in the liquid phase were chosen for these first chemical investigations. Chromatography setups allowing for fast, highly efficient and high-quality chemical separations were developed for the gas phase as well as for the liquid phase chemical identification of SHEs and their homologs. ${ }^{[18]}$ The unambiguous detection of single atoms of transactinide elements was achieved by the development of highly sophisticated, event-by-event $\alpha$ - and SF-spectroscopic setups with silicon-based semiconductor solidstate detectors. A thorough statistical data analysis of these experiments revealed a typical transition-metal behavior for $\mathrm{Rf}$ and $\mathrm{Db}$, similar to the respective homologs in the same groups and hence supporting the predictions from the periodic table. 
It was not until the 1990s that first gas-phase chemical investigations were performed with the next SHE seaborgium $(\mathrm{Sg}, Z=$ 106), carried out by the Swiss group as a part of a large international collaboration at the Gesellschaft für Schwerionenforschung (GSI), Darmstadt, Germany. These experiments revealed a lower volatility of $\mathrm{SgO}_{2} \mathrm{Cl}_{2}$ in comparison to the homologous compounds of the lighter elements Mo and $\mathrm{W}$ in group 6.[23] In parallel, the colleagues from GSI Darmstadt and the University of Mainz investigated the complex formation of $\mathrm{Sg}$ in the aqueous phase using automated ion exchange chromatographic techniques. ${ }^{[23]}$ Correlations of microscopic properties, as observables in gasphase chromatographic experiments with single atoms, with macroscopic properties like sublimation enthalpies or boiling points, allows radiochemists to draw conclusions on the behavior of SHEs at weighable amounts. This approach together with mutual correlations of thermodynamic state functions, among elements and their compounds of group 6, revealed seaborgium as the likely least volatile element in the known periodic table. ${ }^{[24]}$

In 1999/2000 a large international experimental campaign, under the lead of the Swiss researchers and utilizing the Phillips cyclotron at PSI, targeted the first chemical investigation of bohrium $(\mathrm{Bh}, Z=107)$. Roughly 20 years after its discovery, Bh was finally chemically characterized in a gas chromatographic experiment in the form of a volatile oxychloride molecule (presumably $\mathrm{MO}_{3} \mathrm{Cl}$ with ' $\mathrm{M}$ ' being a transition metal of group 7) together with its homologs in group 7, technetium and rhenium. ${ }^{[25]}$ The press commented these findings with 'Boring Bohrium Behaves as Expected'. ${ }^{[26]}$ Nonetheless, these results corroborated the affiliation of bohrium as a typical group 7 element of the periodic table.

Between the years 2000 and 2002, experimental campaigns, again led by researchers from PSI and the University of Bern, went on to study the formation and adsorption chromatographic behavior of hassium tetroxide, i.e. with Hs (hassium, $Z=108$ ) in its highest oxidation state. This study revealed that Hs forms a very volatile tetroxide $\mathrm{HsO}_{4},{ }^{\text {[27] }}$ similar to its lighter homologs in group 8 of the periodic table. The relatively high volatility of $\mathrm{HsO}_{4}$ allowed for an innovation in the field of transactinide chemistry, which is considered to be the most successful approach to this day: By using the surface of the silicon-based solid state detectors directly as the stationary surface of a gas-phase thermochromatography experiment ensured thus far unprecedented efficiencies. The single molecules, carried by a gas stream, were given multiple chances to deposit on separated, sequential detector surfaces held at increasingly low temperatures (i.e. negative temperature gradient from approximately room temperature down to $\approx-160^{\circ} \mathrm{C}$ ). At around $-40^{\circ} \mathrm{C}$ six molecules of $\mathrm{HsO}_{4}$ were retained on the detector surface by adsorbing long enough to measure their unique decay sequence. $\mathrm{OsO}_{4}$ instead, simultaneously produced and investigated, made it further down to temperatures of about $-80{ }^{\circ} \mathrm{C}$, thus identified as more volatile. ${ }^{[27]}$ These results confirmed once more the expected trend ${ }^{[28]}$ in the groups of transition metals towards the heavier members: A generally decreasing volatility of chemical compounds, with the $d$-element in question in its highest oxidation state, was furthermore bolstered.

Only recently, another, more exotic volatile compound class was found suitable to investigate transition metals in the form of metal carbonyl complexes (MCCs). The in situ formation of MCCs was observed when thermalizing single atoms of transition metals in a CO-containing atmosphere. ${ }^{[29]}$ This exciting observation was pursued further with a large experimental campaign, led by the colleagues from GSI Darmstadt and the University of Mainz and focusing on the formation and adsorption behavior of $\mathrm{Sg}(\mathrm{CO})_{6}$. And indeed, this molecule was observed and classified as behaving rather similarly to the carbonyl compounds of lighter group 6 elements tungsten and molybdenum. ${ }^{[30]}$ Such an experiment was only possible due to the introduction of physical pre-separation. ${ }^{[31]}$ Before the dawn of separators with high trans- mission efficiencies, experiments were commonly confronted with the intense heavy-ion beam passing through the chemical reaction chamber, thus exposing the produced and therein thermalized transactinide elements to rather harsh conditions such as an intense plasma. However, the early on deflection of the primary heavy-ion beam used for the production of the transactinides in a separator is instrumental when experimenting with such fragile complexes like MCCs. Meanwhile, the simultaneous, thorough separation of by-products of nuclear fusion is furthermore important for the unambiguous identification of transactinide-related decays by lowering the overall background during nuclear spectroscopic measurements. MCCs are part of the long-term perspective of transactinide research (see Section 3): The chemical bonding in the MCCs is conserving the zero oxidation state of the central SHE atom and thus, it is heavily influenced by relativistic effects, ${ }^{[32]}$ making MCCs an exciting and experimentally assessable study object. ${ }^{[33]}$ This compound class might also deliver first experimental, chemical information on meitnerium $(\mathrm{Mt}, Z=109)$. Apart from that, the noble-metal group members meitnerium, darmstadtium (Ds, $Z=110)$ and roentgenium $(\mathrm{Rg}, Z=111)$ are expected to be not very reactive chemically. As their elemental forms as well as their associated compounds are presumed to be relatively non-volatile, no chemical information has been gathered so far regarding these elements. An interesting possibility however, is discussed below (see Section 3) involving the further development of fast electrochemical methods.

\subsection{Metals with s- and p-Character}

Only the discovery of isotopes of the elements copernicium (Cn, $Z=112$ ), nihonium (Nh, $Z=113$ ) and flerovium (Fl, $Z=$ 114) (for a review see ref. [16a] and for an overview Fig. 1), which are long-lived enough for their chemical investigation $\left(t_{1 / 2}\right.$ $\geq 1 \mathrm{~s}$ ), allowed for first experiments with these SHEs as well. Early predictions had postulated these elements as being metallic. ${ }^{[34]}$ Relativistic effects, particularly the primary relativistic contraction of the electron orbitals with low angular momentum, i.e. $s$ and $p_{1 / 2}$, lead to a relevant energetic stabilization of the elemental atomic states and thus to an increased volatility. Even an inertness comparable to that characterizing noble gases was predicted theoretically for $\mathrm{Cn}$ and $\mathrm{Fl}$ early on. ${ }^{35]}$ These early findings were later on confirmed by quantum chemical computations based on modern relativistic density functional theory (for a review see ref. [36]), which predict high ionization potentials and high promotion energies for both elements. Nonetheless, the formation of metallic bonds towards noble metal surfaces was expected, as it was already predicted semi-quantitatively in 1983.[37] Thus, the experiments to chemically investigate these elements had to address simultaneously the metallic bonding as well as the noble-gas-like, inert behavior. The advancement of the thermochromatography setup of the Heavy Elements group's Cryo-Online Detector (COLD, see Fig. 2), which was initially used for the investigations of $\mathrm{HsO}_{4}$, played an instrumental role. Improvements, such as the coverage of the silicon detector surfaces with gold together with an increased temperature resolution of about $5 \mathrm{~K} /$ detector allowed for the first time to chemically study these new elements. In the course of several experimental campaigns, initiated by the Swiss group in close collaboration with the colleagues from the Flerov Laboratory of Nuclear Reactions (FLNR) in Dubna, Russia, the first chemical investigations of $\mathrm{Cn}^{[38]}$ and $\mathrm{Fl}^{[39]}$ were successfully accomplished. $\mathrm{Cn}$ was characterized as an inert volatile element with a much weaker metallic character compared to its lighter homolog in group 12, i.e. $\mathrm{Hg}$. These results are in agreement with even the most recent theoretical calculations summarized in ref. [36] (and references therein). The surprising observation of an even more inert character of elemental $\mathrm{Fl}$ is in contradiction to these theoretical expectations. Experiments performed later on at GSI using a similar thermo- 


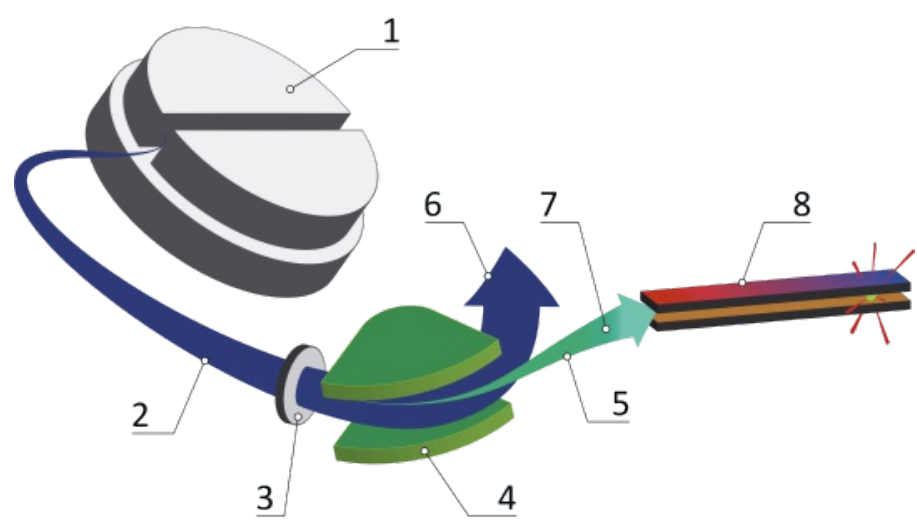

Fig. 2. General scheme of a thermochromatography experiment with SHEs with 1 the cyclotron/accelerator, 2 the heavy-ion beam, 3 the target, 4 the physical pre-separator, 5 the SHEs as nuclear fusion-evaporation products, 6 the primary ion beam and nuclear reaction by-products, 7 an optional chemical reaction, and 8 the chemical separation stage in the form of adsorption thermochromatography with the Cryo OnLine Detector (COLD); indicated on the far right is the decay of a SHE at low temperatures.

chromatographic setup in combination with physical pre-separation, revealed another, more theory-conform behavior: In fact, Fl interacted more strongly with the gold surface on the silicon detectors in comparison to $\mathrm{Cn} .{ }^{[40]}$ However, in a second series of hitherto unpublished experiments, the initial, surprising behavior of flerovium, such as measured at FLNR, was partly reproduced. ${ }^{[41]}$ Nevertheless, open questions remain and are still intensely discussed in the community. There is however, a consensus among all scientists in the field: More data is required for an unambiguous chemical characterization of flerovium. Thereto, important progress was made with the newly built SHE Factory of the FLNR, a recently completed accelerator complex, which is currently under commission. The new facility was erected with the sole purpose of synthesizing and characterizing SHEs and holds promise for experiments with unprecedented statistical significance. ${ }^{[42]}$ In fact, the Swiss-Russian investigation on the volatility of flerovium (as well as copernicium) was selected to be the very first chemistry experiment with highest priority at this new facility.

Meanwhile, the radiochemists from the FLNR took the lead concerning the very first chemistry experiments with nihonium. ${ }^{[43]}$ During these experiments, a volatile chemical species of Nh was transported at $70^{\circ} \mathrm{C}$ over a Teflon surface to a gold-covered detection device, similar to the above introduced COLD array. Therein, the transported species permanently adsorbed at room temperature and was finally identified by its unique decay pattern. The experiments were repeated using physical pre-separation to enforce the elemental state ${ }^{[4]}$ and later on continued with studies targeting the most likely chemical form of Nh under the applied experimental conditions, i.e. the monohydroxide $\mathrm{NhOH} .{ }^{[45]}$ In the latter chemical species, $\mathrm{Nh}$ is found in its oxidation state $+\mathrm{I}$, which is presumed to be the most stable oxidation state of heavier group 13 elements. The relativistic stabilization of the $7 s$-orbital in $\mathrm{Nh}$ leads to a quasi-inertness of those electrons (inert pair effect), similar to the $6 s$-valence shell of the group-13-homolog thallium with its predominant oxidation state + I. ${ }^{46]}$

So far, no elements beyond $Z=114$ have been chemically studied. This is mainly due to the extremely short half-lives (see Fig. 1) of the recently discovered radioisotopes of elements moscovium ( $\mathrm{Mc}, Z=115$ ), livermorium ( $\mathrm{Lv}, Z=116$ ), tennessine (Ts, $Z=117)$ and oganesson $(\mathrm{Og}, Z=118)$. The chemical assessment of these elements will require entirely new, ultra-fast chemical investigation techniques, which are currently under development (see Section 3).

\section{A Roadmap to the Future}

The periodic table of elements (see Fig. 3) may serve as the perfect roadmap for future research on the chemistry of SHEs. ${ }^{28]}$ So far, only a few chemical properties are known for the transactinide series. For the lighter transactinide $d$-elements only chemical species with the SHE in its highest oxidation state have been investigated. Meanwhile, $\mathrm{Cn}$ and the first two $p$-elements were mostly studied in their elemental state.

Recently, the MCC-formation (see Section 2) offered a unique opportunity to experimentally address the binding energy of a compound of a transactinide $d$-element with the central atom in the zero oxidation state. Theoretical calculations revealed contradicting predictions for the bond strength in $\mathrm{Sg}(\mathrm{CO})_{6}$ due to challenges arising from a strong influence of relativistic effects on the stability of the binding in such fragile molecules. ${ }^{[48]}$ Therefore, comparative thermal stability studies of group 6 MCCs were initiated. These efforts address directly the first carbonyl bond dissociation energy by means of isothermal decomposition chromatography. ${ }_{.}^{[33,49]}$ A first experiment with $\mathrm{Sg}(\mathrm{CO})_{6}$ proved the feasibility of such a study on the single-atom-per-hour level. Recent systematic studies of all involved experimental parameters using the Fast On-line Reaction Apparatus (FORA) revealed a number of possibilities on how to further increase the formation and transport yields of MCCs. ${ }^{[50]}$ Therefore, even experiments with the heavier transactinide elements Bh as well as Hs and Mt are within reach upon solid preparation.
Periodic Table of the Elements

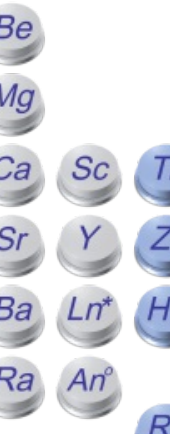

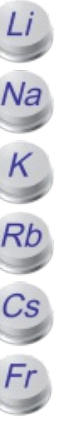

*Lanthanides

${ }^{\circ}$ Actinides
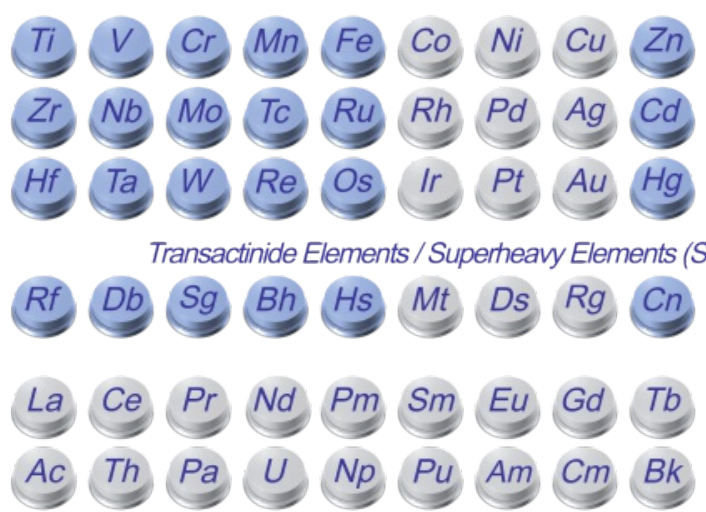

Transactinide Elements / Superheavy Elements (SHEs)

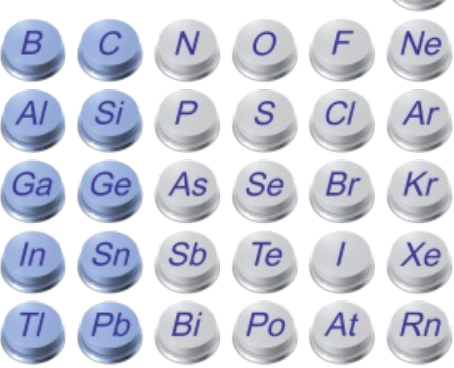

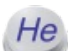

Ne

$\mathrm{Kr}$ once.
Fig. 3. Periodic table of the elements (Nomenclature IUPAC 2019, see ref. [47]); colored are the groups for which the chemistry of the corresponding transactinide has been investigated at least 
Furthermore, the discovery of radioisotopes of elements Bh to $\mathrm{Rg}$ with half-lives up to a couple of minutes holds promise for 'less boring' (and first time) chemical investigations of these elements. The focus of these studies shall be on electrochemistry $^{[51]}$ as well as on compounds with the SHE preserved in lower oxidation states. ${ }^{[52]}$ For both cases, the stabilization of defined chemical species and the kinetic effects during their formation and transport are the most challenging tasks to be addressed. For instance, in preparatory experiments for group 7 and group 8 transactinides, $\mathrm{Bh}^{[53]}$ and $\mathrm{Hs}^{,{ }^{[54]}}$ it was observed that the oxidation of these elements to high oxidation states in oxygen and water-containing reactive gases is, despite being thermodynamically favored, severely kinetically hindered, i.e. an observation possibly interesting for further investigations. In particular for electrochemical investigations, the ion mobility and reaction kinetics in selected electrolytes have to be investigated to identify the best suitable system for first chemical investigations of the noble metal elements Mt, Ds, and Rg. In fact, the best electrolyte might not be aqueous ${ }^{[51]}$ but instead based on ionic liquids operated at elevated temperatures. ${ }^{[55]}$ This highlights once more the importance of systematic model experiments with the homologs of SHEs, to reveal the most suitable and best described chemical system for the challenging investigation of transactinide elements at a few-atoms-per-day scale.

An additional development brought forward by the Swiss researchers from PSI regards the detection of SHEs in rough chemical environments as well as at high temperatures. Thus, the in-house fabrication and employment of wide band-gap semiconductors such as diamond ${ }^{[56]}$ or silicon carbide (i.e. the $4 \mathrm{H}-\mathrm{SiC}$ polytype $)^{[57]}$ as detector materials for $\alpha$ - and SF-spectroscopy paved the way to unprecedented possibilities for chemistry experiments with SHEs: For example, electrochemistry experiments can be performed directly on the detector surface (e.g. by using the detector surface as an electrode), or they can be utilized for the in situ detection of non-volatile, low-oxidation-state compounds of the lighter transactinides. Another important field of application of these detector developments concerns the chemical investigations of the latest members of the seventh row of the periodic table: The elements moscovium up to oganesson were discovered in ${ }^{48} \mathrm{Ca}$-induced nuclear fusion-evaporation reactions ${ }^{[13 c]}$ in combination with targets of heaviest actinide elements up to ${ }^{249} \mathrm{Bk}$ (these actinide elements are still assessable in milligram amounts). So far, all produced radioisotopes of these transactinide elements feature half-lives exclusively in the millisecond range (see Fig. 1). The limited life times of these radionuclides is likely the most challenging part of their chemical investigation. Thus, the Heavy Elements group at PSI pursues the development of on-line vacuum chromatographic methods. ${ }^{[58]}$ Despite the obvious gain in terms of chromatographic transport and deposition speeds in the molecular flow regime, several experimental challenges have to be mastered. Firstly, the production of transactinide elements leads to nuclear fusion products, which recoil from the target with the momentum of the incident ion beam particles. Whereas, in a 'classical' gas-phase experiment, these recoils can be thermalized in the course of multiple collisions with gas particles, and an entirely different approach is necessary in vacuo. Therein, the nuclear reaction products may be implanted into a solid catcher and subsequently be rapidly released at highest possible temperatures. For this purpose, model studies with lighter homologs of different SHEs have assisted to identify ideal catcher materials for the different elements and have helped to understand the processes governing their fast thermal release. ${ }^{[59]}$ Secondly, ultra-fast vacuum chromatographic investigations rely on high-temperature designs in order for them to push the adsorption retention down into the millisecond time domain. Therefore, whenever possible, predictions of adsorption properties from quantum chemical computations based on relativistic density functional theory ${ }^{[36]}$ can be used in conjunction with Monte-Carlo-based models of vacuum chromatography ${ }^{[58]}$ to predict the required temperature scales. In addition to the quantum chemical computations and in case of metallic transactinides, semi-empirical solutions based on the Eichler-Miedema model can provide valuable information on the adsorption properties of those SHEs on metal surfaces, and thus, can assist in selecting a suitable stationary phase (i.e. the chromatographic surface).[37] These stationary surfaces need to be heated to higher temperatures in order to enable the characterization of relatively less-volatile chemical species than, e.g. elemental $\mathrm{Cn}$ and $\mathrm{Fl}$ (such as expected for the elements $\mathrm{Nh}, \mathrm{Mc}, \mathrm{Lv}$, and Ts as well as compounds of those). This, together with the prerequisite of an in situ detection of the specific, genetically-linked $\alpha$-decay patterns of the short-lived radionuclides for an unambiguous identification of the SHE in question can be only achieved with the application of the above introduced wide band-gap semiconductors. These henceforth rather well-established detector materials replace the commonly applied Si-based detector technology[56,57] and enable measurements in environments previously beyond reach, i.e. either directly heated to temperatures $T>50{ }^{\circ} \mathrm{C}$ in a thermochromatography detector array or operated in the form of an escape detector for isothermal chromatography in the vicinity of IR-vis-UV-emitting surfaces of hot materials. ${ }^{[58]}$

Another strategy towards achieving highest speeds for the investigation of transactinides with half-lives in the order of tens of milliseconds is connected to electromagnetic, single-ion handling, which follows their production, either directly after e.g. a gasfilled separator, ${ }^{[60]}$ or behind gas catchers and/or ion traps, ${ }^{[61]}$ the latter both likewise succeeding physical pre-separation. Here, the challenges are manifold too. Apart from the still rather moderate efficiencies of gas catchers, the establishment of chemical equilibria, which is a prerequisite for the physicochemical assessment, is almost impossible. Therefore, direct results from such in situ chemical investigation methods of ions will be limited to kinetic reaction rates of unimolecular and bimolecular reactions of ions. Hence, in order to quantify thermochemical properties from experimental observations, new models are required based on nonequilibrium thermodynamics, which include excited atomic and molecular states, such as the Rice-Ramsperger-Kassel-Marcus (RRKM) theory. ${ }^{[62]}$ Modern chemical theory has to heavily assist here for a correct thermodynamic description addressing the excited ionic and molecular states involved. ${ }^{[63]}$ Last but not least, ion manipulation may be a promising technique to introduce single atoms into a vacuum chromatographic system, which would allow the time consuming step of solid-state thermal release of implanted SHEs from hot catcher materials to be avoided. The likely challenges of operating a spectroscopic detection system in the vicinity of high-frequency electromagnetic fields of gas catchers and similar equipment has yet to be mastered, since large distance transports are not possible with radionuclides surviving for a few milliseconds only.

\section{Conclusion}

This short introduction to the field of transactinide chemistry is intended to highlight the multi-disciplinarity of this exciting field at the forefront of fundamental science. This thrilling and stimulating research topic not only offers exciting prospects for young researchers in nuclear sciences and engineering, but also relies on the international collaboration of research institutions across the globe. Only based on these well-established joint efforts, will scientists be able to reveal exciting new properties of SHEs in the years to come. These findings will enhance our fundamental understanding of the chemical behavior, not only of the heaviest elements, but of all elements in the periodic table and beyond. Swiss radiochemistry, well embedded into the large research infrastructure at the Paul Scherrer Institute, will continue to contribute with high-impact experiments, thus keeping a leading position in the field of transactinide chemistry. 


\section{Acknowledgements}

The authors would like to acknowledge the enduring financial support by the SNSF as well as the staff of the numerous accelerator facilities, which are instrumental for the production of SHEs and exotic isotopes of their lighter homologs, i.e. at the Flerov Laboratory of Nuclear Reactions (as part of the Joint Institute for Nuclear Research), Dubna, Russia, the GSI Helmholtzzentrum für Schwerionenforschung, Darmstadt, Germany, the Japan Atomic Energy Agency in Tokai-mura, Japan, the RIKEN Nishina Center for Accelerator-Based Science, Wakoshi, Japan, the Lawrence Berkeley National Laboratory, Berkeley, USA, and at the Paul Scherrer Institute in Villigen PSI, Switzerland.

Received: July 30, 2020

[1] D. I. Mendeleev, J. Russ. Chem. Soc. 1869, 1, 60 (in Russian).

[2] D. I. Mendeleev, Z. für Chem. 1869, 12, 405 (in German).

[3] L. Meyer, 'Die modernen Theorien der Chemie' Verlag von Maruschke \& Berendt, 1864

[4] E. R. Scerri, 'The Periodic Table - Its Story and Its Significance', Oxford University Press, 2007

[5] a) P. J. Karol, R. C: Barber, B. M. Sherrill, E. Verdaci, T. Yamazaki, Pure Appl. Chem. 2016, 88, 139, https://doi.org/10.1515/pac-2015-0502; b) P. J. Karol, R. C: Barber, B. M. Sherrill, E. Verdaci, T. Yamazaki, Pure Appl. Chem. 2016, 88, 155, https://doi.org/10.1515/pac-2015-0501.

[6] a) H. G. J. Moseley, Philos. Mag. 1913, 26, 1024, https://doi.org/10.1080/14786440408635141; b) H. G. J. Moseley, Philos. Mag. 1914, 27, 703, https://doi.org/10.1080/14786440408635141.

[7] a) E. Schrödinger, Ann. Phys. 1926, 384, 361, https://doi.org/10.1002/andp.19263840404; b) E. Schrödinger, Ann. Phys. 1926, 384, 489, https://doi.org/10.1002/ andp.19263840602; c) E. Schrödinger, Ann. Phys. 1926, 385, 437, h t t p s://doi.org/10.1002/andp.19263851302; d) E. Schrödinger, Ann. Phys. 1926, 386, 109, https://doi.org/10.1002/andp.19263861802.

[8] A. Einstein, Ann. Phys. 1905, 322, 891, https://doi.org/10.1002/andp.19053221004.

[9] P. A. M. Dirac, Proc. R. Soc. Lond. A 1929, 123, 714, https://doi.org/10.1098/rspa.1929.0094.

[10] P. Pyykkö, J.-P. Desclaux, Acc. Chem. Res. 1979, 12, 276, https://doi.org/10.1021/ar50140a002.

[11] a) B. Fricke, J. T. Waber, Actinides Rev. 1971, 1, 433; b) P. Pyykkö, Chem. Rev. 1988, 88, 563; c) V. P. Pershina, Chem. Rev. 1996, 96, 1977; d) V. Pershina, 'Theoretical Chemistry of the Heaviest Elements' in 'The Chemistry of Superheavy Elements', Eds. M. Schädel, D. Shaughnessy, Springer-Verlag Berlin Heidelberg, 2014.

[12] I. Zvara, Yu. T. Chuburkov, R. Tsaletka, T. S. Zvarova, M. R. Shalaevski, B. V. Shilov, Atomn. Energ. 1966, 21, 83.

[13] K. Behringer, A. Grütter, H. R. von Gunten, A. Schmid, A Wyttenbach, B. Hahn, U. Noser, H. W. Reist, Phys. Rev. C 1974, 9, 48, https://doi.org/10.1103/PhysRevC.9.48.

[14] Yu. Ts. Oganesyan, Herald Russ. Acad. Sci. 2011, 81, 591, https://doi.org/10.1134/S1019331611060116.

[15] G. M. Ter-Akopian, S. N. Dmitriev, Nucl. Phys. A 2015, 944, 177 https://doi.org/10.1016/j.nuclphysa.2015.09.004.

[16] a) Yu. Ts. Oganessian, V. K. Utyonkov, Nucl. Phys. A 2015 , 944, 62, https://doi.org/10.1016/j.nuclphysa.2015.07.003; b) V. I. Zagrebaev, W. Greiner, Nucl. Phys. A 2015, 944, 257, https://doi.org/10.1016/j.nuclphysa.2015.02.010; c) J. B. Roberto, C. W. Alexander, R. A. Boll, J. D. Burns, J. G. Ezold, L. K. Felker, S. L. Hogle, K. P. Rykaczewski, Nucl. Phys. A 2015, 944, 99, https://doi.org/10.1016/j.nuclphysa.2015.06.009;

Hofmann, G. Münzenberg, Rev. Mod. Phys. 2000, 72 (3), 733 https://doi.org/10.1103/RevModPhys.72.733.

[17] J. Magill, R. Dreher, Z. Soti, 'Karlsruhe Nuclide Chart', Nucleonica GmbH, 2018, https://www.nucleonica.com

[18] a) 'The Chemistry of Superheavy Elements', Eds. M. Schädel, D. Shaughnessy, Springer-Verlag Berlin Heidelberg, 2014; b) A. Türler, V. Pershina, Chem. Rev. 2013, 113, 1237, https://doi.org/10.1021/cr3002438

[19] https://www.psi.ch/en/nis

[20] M. Wachsmuth, B. Eichler, L. Tobler, D. T. Jost, H. W. Gäggeler, M. Ammann, Radiochim. Acta 2000, 88, 873, https://doi.org/10.1524/ract.2000.88.12.873.

[21] N. P. van der Meulen, R. Eichler, P. V. Grundler, R. Hasler, W. Hirzel, S. Joray, D. C. Kiselev, R. Sobbia, A. Sommerhalder, Z. Talip, H. Zhang, S. Braccini, 'The Use of PSI's IP2 Beam Line Towards Exotic Radionuclide Development and its Application Towards Proof-Of-Principle Preclinical and Clinical Studies', in 'Proc. Cyclotrons'19', Eds. L. Conradie, J. G. De Villiers, V. R. W. Schaa, JACoW Publishing Geneva Switzerland, 2019, https://doi.org/10.18429/JACoW-Cyclotrons2019-TUA03.
[22] a) I. Usoltsev, R. Eichler, R. Dressler, D. Piguet. D. Wittwer, A. Türler, R. Brütsch, E. A. Olsen, J. P. Omtvedt, A. Semchenkov, Nucl. Instrum. Methods Phys. Res., Sect. A 2012, 691, 5, https://doi.org/10.1016/j.nima.2012.06.060; b) I. Usoltsev, R. Eichler, G. K. Vostokin, A. V. Sabel'nikov, N.V. Aksenov, Yu. V. Albin, G. A. Bozhikov, V. I. Chepigin, S. N. Dmitriev, V. Ya. Lebedev, O. N. Malyshev, O. V. Petrushkin, D. Piguet, G. Ya. Starodub, A. I. Svirikhin, A. Türler, A. V. Yeremin, Nucl. Instrum. Methods Phys. Res., Sect. B 2014, 318, 297, https://doi.org/10.1016/j.nimb.2013.10.019.

[23] M. Schädel, W. Brüchle, R. Dressler, B. Eichler, H. W. Gäggeler, R. Günther, K. E. Gregorich, D. C. Hoffman, S. Hübener, D. T. Jost, J. V. Kratz, W. Paulus, D. Schumann, S. Timokhin, N. Trautmann, A. Türler, G. Wirth, A. Yakuschev, Nature 1997, 388, 55, https://doi.org/10.1038/40375.

[24] a) A. Türler, W. Brüchle, R. Dressler, B. Eichler, R. Eichler, H. W. Gäggeler, M. Gärtner, J.-P. Glatz, K. E. Gregorich, S. Hübener, D. T. Jost, V. Y. Lebedev, V. G. Pershina, M. Schädel, S. Taut, S. N. Timokhin, N. Trautmann, A. Vahle, A. B. Yakushev, Angew. Chem. Int. Ed. 1999, 38, 2212, https://doi.org/10.1002/(SICI)1521-3773(19990802)38:15<2212::AIDANIE2212>3.0.CO;2-6; b) B. Eichler, A. Türler, H. W. Gäggeler, J. Phys. Chem. A 1999, 103, 9296, https://doi.org/10.1021/jp9917751.

[25] R. Eichler, W. Brüchle, R. Dressler, Ch. E. Düllmann, B. Eichler, H. W. Gäggeler, K. E. Gregorich, D. C. Hoffman, S. Hübener, D. T. Jost, U. W. Kirbach, C. A. Laue, V. M. Lavanchy, H. Nitsche, J. B. Patin, D. Piguet, M. Schädel, D. A. Shaughnessy, D. A. Strellis, S. Taut, L. Tobler, Y. S Tsyganov, A. Türler, A. Vahle, P. A. Wilk, A. B. Yakushev, Nature 2000, 407, 63, https://doi.org/10.1038/35024044

[26] https://www.sciencemag.org/news/2000/08/boring-bohrium-behaves-expected

[27] Ch. E. Düllmann, W. Brüchle, R. Dressler, K. Eberhardt, B. Eichler, R. Eichler, H. W. Gäggeler, T. N. Ginter, F. Glaus, K. E. Gregorich, D. C. Hoffman, E. Jäger, D. T. Jost, U. W. Kirbach, D. M. Lee, H. Nitsche, J. B. Patin, V. Pershina, D. Piguet, Z. Qin, M. Schädel, B. Schausten, E. Schimpf, H.-J. Schött, S. Soverna, R. Sudowe, P. Thörle, S. N. Timokhin, N. Trautmann, A. Türler, A. Vahle, G. Wirth, A. B. Yakushev, P. M. Zielinski, Nature 2002, 418, 859, https://doi.org/10.1038/nature00980.

[28] R. Eichler, Radiochim. Acta 2019, 107, 865 , https://doi.org/10.1515/ract-2018-3080.

[29] J. Even, A. Yakushev, Ch. E. Düllmann, J. Dvorak, R. Eichler, O. Gothe, D. Hild, E. Jäger, J. Khuyagbaatar, J. V. Kratz, J. Krier, L. Niewisch, H. Nitsche, I. Pysmenetska, M. Schädel, B. Schausten, A. Türler, N. Wiehl, D. Wittwer, Inorg. Chem. 2012, 51, 6431, https://doi.org:10.1021/ic300305m.

[30] J. Even, A. Yakushev, Ch. E. Düllmann, H. Haba, M. Asai, T. K. Sato, H. Brand, A. Di Nitto, R. Eichler, F. L. Fan, W. Hartmann, M. Huang, E. Jäger, D. Kaji, J. Kanaya, Y. Kaneya, J. Khuyagbaatar, B. Kindler, J. V. Kratz, J. Krier, Y. Kudou, N. Kurz, B. Lommel, S. Miyashita, K. Morimoto, K. Morita, M. Murakami, Y. Nagame, H. Nitsche, K. Ooe, Z. Qin, M. Schädel, J. Steiner, T. Sumita, M. Takeyama, K. Tanaka, A. Toyoshima, K. Tsukada, A. Türler, I. Usoltsev, Y. Wakabayashi, Y. Wang, N. Wiehl, S. Yamaki, Science 2014, 345, 1491

[31] Ch. E. Düllmann, Eur. Phys. J. D 2007, 45, 75 , https://doi.org:10.1140/epjd/e2007-00033-9.

[32] V. Pershina, J. Anton, J. Chem. Phys. 2013, 138, 174301, https://doi.org/10.1063/1.4802765

33] I. Usoltsev, R. Eichler, Y. Wang, J. Even, A. Yakushev, H. Haba, M. Asai, H. Brand, A. Di Nitto, Ch. E. Düllmann, F. Fangli, W. Hartmann, M. Huang, E. Jäger, D. Kaji, J. Kanaya, Y. Kaneya, J. Khuyagbaatar, B. Kindler, J. V. Kratz, J. Krier, Y. Kudou, N. Kurz, B. Lommel, S Miyashita, K. Morimoto, K. Morita, M. Murakami, Y. Nagame, H Nitsche, K. Ooe, T. K. Sato, M. Schädel, J. Steiner, P. Steinegger, T. Sumita, M. Takeyama, K. Tanaka, A. Toyoshima, K. Tsukada, A. Türler, Y. Wakabayashi, N. Wiehl, S. Yamaki, Z. Qin, Radiochim. Acta 2016, 104, 141 https://doi.org/10.1515/ract-2015-2445.

[34] a) B. Eichler, Kernenergie 1976, 19, 307; b) B. Eichler, T. Reetz, Kernenergie 1982, 25, 218.

[35] K. S. Pitzer, J. Chem. Phys. 1975, 63,1032, https://doi.org:10.1063/1.431398,

[36] V. Pershina, Inorg. Chem. 2018, 57, 3948, https://doi.org/10.1021/acs.inorgchem.8b00101.

[37] B. Eichler, H. Rossbach, Radiochim. Acta 1983, 33, 121, https://doi.org/10.1524/ract.1983.33.23.121.

[38] a) R. Eichler, N. V. Aksenov, A. V. Belozerov, G. A. Bozhikov, V. I. Chepigin, S. N. Dmitriev, R. Dressler, H. W. Gäggeler, V. A. Gorshkov, F. Haenssler, M. G. Itkis, A. Laube, V. Ya. Lebedev, O. N. Malyshev, Yu. Ts. Oganessian, O. V. Petrushkin, D. Piguet, P. Rasmussen, S. V. Shishkin, A. V. Shutov, A. I. Svirikhin, E. E. Tereshatov, G. K. Vostokin, M. Wegrzecki, A V. Yeremin, Nature 2007, 447, 72, https://doi.org/10.1038/nature05761; b) R. Eichler, N. V. Aksenov, A. V. Belozerov, G. A. Bozhikov, V. I. Chepigin, S. N. Dmitriev, R Dressler, H. W. Gäggeler, A. V. Gorshkov, M. G. Itkis, F. Haenssler, A. Laube, V. Ya. Lebedev, O. N. Malyshev, Yu. Ts. Oganessian, O. V. Petrushkin, D. Piguet, A. G. Popeko, P. Rasmussen, S. V. Shishkin, A, A. Serov, A. V. Shutov, A. I. Svirikhin, E. E. Tereshatov, G. K. Vostokin, M. Wegrzecki, A. V. Yeremin, Angew. Chem. Int. Ed. 2008, 47, 3262, https://doi.org/10.1002/anie.200705019.

[39] R. Eichler, N. V. Aksenov, Yu. V. Albin, A. V. Belozerov, G. A. Bozhikov, V. I. Chepigin , S. N. Dmitriev, R. Dressler, H. W. Gäggeler, V. A. Gorshkov, 
R. A. Henderson, A. M. Johnsen, J. M. Kenneally, V. Ya. Lebedev, O. N. Malyshev, K. J. Moody, Yu. Ts. Oganessian, O. V. Petrushkin, D. Piguet, A. G. Popeko, P. Rasmussen, A. Serov, D. A. Shaughnessy, S. V. Shishkin, A V. Shutov, M. A. Stoyer, N. J. Stoyer, A. I. Svirikhin, E. E. Tereshatov, G. K. Vostokin, M. Wegrzecki, P. A. Wilk, D. Wittwer, A. V. Yeremin, Radiochim. Acta 2010, 98, 133, https://doi.org/10.1524/ract.2010.1705.

[40] A. Yakushev, J. M. Gates, A. Türler, M. Schädel, Ch. E. Düllmann, D. Ackermann, L.-L. Andersson, M. Block, W. Brüchle, J. Dvorak, K. Eberhardt, H. G. Essel, J. Even, U. Forsberg, A. Gorshkov, R. Graeger, K. E. Gregorich, W. Hartmann, R.-D. Herzberg, F. P. Heßberger, D. Hild, A. Hübner, E. Jäger, J. Khuyagbaatar, B. Kindler, J. V. Kratz, J. Krier, N. Kurz, B. Lommel, L. J. Niewisch, H. Nitsche, J. P. Omtvedt, E. Parr, Z. Qin, D. Rudolph, J. Runke, B. Schausten, E. Schimpf, A. Semchenkov, J. Steiner, P. Thörle-Pospiech, J. Uusitalo, M. Wegrzecki, N. Wiehl, Inorg. Chem. 2014, 53, 1624, https://doi.org/10.1021/ic4026766.

[41] L. Lens, PhD Thesis, University of Mainz, ID 1000034136, 2018

[42] a) S. N. Dmitriev, M. G. Itkis, Yu. Ts. Oganessian, EPJ Web of Conferences 2016, 131, 08001, https://doi.org:10.1051/epjconf/201613108001; b) Yu. Ts. Oganessian, S. N. Dmitriev, V. K. Utyonkov, 'Project of Priority Experiments at SHE Factory' in 'Proceedings, $9^{\text {th }}$ International Symposium on Exotic Nuclei (EXON-2018)', Eds. Yu. E. Penionzhkevich, Yu. E. Sobolev, 2020, https://doi.org/10.1142/9789811209451_0061.

[43] S. N. Dmitriev, N. V. Aksenov, Yu. V. Albin, G. A. Bozhikov, M. L. Chelnokov, V. I. Chepigin, R. Eichler, A. V. Isaev, D. E. Katrasev, V. Ya. Lebedev, O. N. Malyshev, O. V. Perushkin, L. S. Porobanuk, M. A. Ryabinin, A. V. Sabel'nikov, E. A. Sokol, A. V. Svirikhin, G. Ya. Starodub, I. Usoltsev, G. K. Vostokin, A. V. Yeremin, Mendeleev Commun. 2014, 24, 253 , https://doi.org/10.1016/j.mencom.2014.09.001.

[44] N. V. Aksenov, P. Steinegger, F. Sh. Abdullin, Yu. V. Albin, G. A. Bozhikov, V. I. Chepigin, R. Eichler, V. Ya. Lebedev, A. Sh. Madumarov, O. N. Malyshev, O. V. Petrushkin, A. N. Polyakov, Yu. A. Popov, A. V. Sabel'nikov, R. N. Sagaidak, I. V. Shirokovsky, M. V. Shumeiko, G. Ya. Starodub, Y. S. Tsyganov, V. K. Utyonkov, A. A. Voinov, G. K. Vostokin, A. V. Yeremin, S. N. Dmitriev, Eur. Phys. J. A 2017, 53, 158, https://doi.org/10.1140/epja/i2017-12348-8.

[45] P. Steinegger, N. V. Aksenov, Yu. V. Albin, Z. Asfari, A. Y. Bodrov, G. A Bozhikov, V. I. Chepigin, I. Chuprakov, R. Dressler, R. Eichler, B. Gall, S. N. Gustova, D. Herrmann, P. Ionescu, A. V. Isaev, B. Kraus, A. Sh. Madumarov, O. N. Malyshev, Y. Melnik, D. Piguet, Yu. A. Popov, A. V. Sabel'nikov, T. K. Sato, A. I. Svirikhin, M. G. Voronyuk, A. V. Yeremin, S. N. Dmitriev, to be submitted.

[46] V. Pershina, M. Iliaš, Chem. Phys. Lett. 2018, 694, 107, https://doi.org/10.1016/j.cplett.2018.01.045.

[47] https://iupac.org/what-we-do/periodic-table-of-elements/

[48] a) C. S. Nash, B. E: Bursten, J. Am. Chem. Soc. 1999, 121, 10830, https://doi.org/10.1021/ja9928273; b) M. Ilias, V. Pershina, Inorg. Chem. 2017, 56, 1638, https://doi.org/10.1021/acs.inorgchem.6b02759.

[49] I. Usoltsev, R. Eichler, A. Türler, Radiochim. Acta 2016, 104, 531, https://doi.org/10.1515/ract-2015-2445.

[50] a) Y. Wittwer, R. Eichler, D. Herrmann, A. Türler, Radiochim. Acta 2020, submitted; b) Y. Wittwer, PhD Thesis, University of Bern, 2020.

[51] a) B. Eichler, J. V. Kratz, Radiochim. Acta 2000, 88, 475, https://doi.org/10.1524/ract.2000.88.8.475; b) H. Hummrich, N. L. Banik, M. Breckheimer, W. Brüchle, Radiochim. Acta 2008, 96, 73, https://doi.org:10.1524/ract.2008.1473; c) A. Toyoshima, Y. Kasamatsu, K. Tsukada, M. Asai, Y. Kitatsuji, Y. Ishii, H. Toume, I. Nishinaka, H. Haba, K. Ooe. W. Sato, A. Shinohara, K. Akiyama, Y. Nagame, J. Am. Chem. Soc. 2009, 131, 9180, https://doi.org/10.1021/ja9030038.

[52] a) L. I. Guseva, G. S. Tikhomirova, G. V. Buklanov, Z. Z. Phar, I. A. Lebedev, N. V. Katargin, B. F. Myasoedov, J. Radioanal. Nucl. Chem. 1987, 117, 205, https://doi.org/10.1007/BF02165793; b) A. Toyoshima, K. Ooe, S. Miyashita, M. Asai, M. F. Attallah, N. Goto, N. S. Gupta, H Haba, M. Huang, J. Kanaya, Y. Kaneya, Y. Kasamatsu, Y. Kitatsuji, Y. Kitayama, K. Koga, Y. Komori, T. Koyama, J. V. Kratz, H. V. Lerum, Y.
Oshimi, V. Pershina, D. Sato, T. K. Sato, Y. Shigekawa, A. Shinohara, A. Tanaka, K. Tsukada, S. Tsuto, T. Yokokita, A. Yokoyama, J. P. Omtvedt, Y. Nagame, M. Schädel, J. Radioanal. Nucl. Chem. 2015, 303, 1169 , https://doi.org/10.1007/s10967-014-3438-X.

[53] R. Eichler, B. Eichler, H. W. Gäggeler, D. T. Jost, R. Dressler, A. Türler, Radiochim. Acta 1999, 87, 151, https://doi.org/10.1524/ract.1999.87.34.151.

[54] U. Rieth, A. Herlert, J. V. Kratz, L. Schweikhard, M. Vogel, C. Walther, Radiochim. Acta 2002, 90, 337, https://doi.org/10.1524/ract.2002.90.6.337.

[55] 'Electrochemistry in Ionic Liquids Vol. 2 Applications', Ed. A. A. J. Torriero, Springer International Publishing Switzerland, 2015.

[56] P. Steinegger, R. Dressler, R. Eichler, D. Piguet, S. Streuli, A Türler, Nucl. Instrum. Methods Phys. Res., Sect. A 2017, 850, 61, https://doi.org/10.1016/j.nima.2016.12.014.

[57] B. Kraus, PhD Thesis, University of Bern, 2020.

[58] P. Steinegger, M. Asai, R. Dressler, R. Eichler, Y. Kaneya, A. Mitsukai, Y. Nagame, D. Piguet, T. K. Sato, M. Schädel,S. Takeda, A. Toyoshima, K. Tsukada, A. Türler, A. Vascon, J. Phys. Chem. C 2016, 120, 7122 , https://doi.org/10.1021/acs.jpcc.5b12033.

[59] a) D. Wittwer, R. Dressler, R. Eichler, H. W. Gäggeler, D. Piguet, A. Türler, Nucl. Instrum. Methods Phys. Res., Sect. B 2013, 297, 86, https://doi.org/10.1016/j.nimb.2012.11.021; b) D. Wittwer, R. Dressler, R. Eichler, H.W. Gäggeler, A. Türler, Radiochim. Acta 2013, 101, 211 , https://doi.org/10.1524/ract.2013.2027

[60] a) Yu. Ts. Oganessian, V. K. Utyonkov, Yu. V. Lobanov, F. Sh. Abdullin, A. N. Polyakov, I. V. Shirokovsky, Yu. S. Tsyganov, A. N. Mezentsev, S. Iliev, V. G. Subbotin, A. M. Sukhov, G. V. Buklanov, K. Subotic, Yu. A. Lazarev, K. J. Moody, J. F. Wild, N. J. Stoyer, M. A Stoyer, R. W. Lougheed, C. A. Laue, Phys. Rev. C 2001, 64, 064309. https://doi.org/10.1103/PhysRevC.64.064309; b) K. E. Gregorich, W Loveland, D. Peterson, P. M. Zielinski, S. L. Nelson, Y. H. Chung, Ch. E. Düllmann, C. M. Folden III, K. Aleklett, R. Eichler, D. C. Hoffman, J. P. Omtvedt, G. K. Pang, J. M. Schwantes, S. Soverna, P. Sprunger, R. Sudowe, R. E. Wilson, H. Nitsche, Phys. Rev. C 2005, 72, 014605 , https://doi.org/10.1103/PhysRevC.72.014605.

[61] a) J.M. Gates, G. K. Pang, J.L. Pore, K.E. Gregorich, J.T. Kwarsick, G. Savard, N.E. Esker, M. Kireeff Covo, M.J. Mogannam, J.C. Batchelder, D.L. Bleuel, R.M. Clark, H.L. Crawford, P. Fallon, K. K Hubbard, A.M. Hurst, I.T. Kolaja, A.O. Macchiavelli, C. Morse, R. Orford, L. Phair, M.A. Stoyer, Phys. Rev. Lett. 2018, 121, 222501, https://doi.org/10.1103/PhysRevLett.121.222501; b) G. Savard, J Clark, C. Boudreau, F. Buchinger, J. E. Crawford, H. Geissel, J. P. Greene, S. Gulick, A. Heinz, J. K. P. Lee, A. Levand, M. Maier, G. Münzenberg, C. Scheidenberger, D. Seweryniak, K. S. Sharma, G. Sprouse, J. Vaz, J. C. Wang, B. J. Zabransky, Z. Zhou, the S258 Collaboration, Nucl. Instrum. Methods Phys. Res., Sect. B 2003, 204, 582 , https://doi.org/10.1016/s0168-583x(02)02134-1.

[62] R. A. Marcus, Phil. Trans. R. Soc. Lond. A 1990, 332, 95 , https://doi.org/10.1098/rsta.1990.0115.

[63] a) U. Kaldor, E. Eliav, Adv. Quantum Chem. 1998, 31, 313, https://doi.org/10.1016/S0065-3276(08)60194-X; b) A. Borschevsky, F Pasteka, V. Pershina, E. Eliav, U. Kaldor, Phys. Rev. A 2015, 91, 020501, https://doi.org/10.1103/PhysRevA.91.020501.

\section{License and Terms}

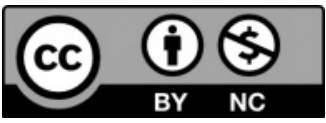

This is an Open Access article under the terms of the Creative Commons Attribution License CC BY_NC 4.0. The material may not be used for commercial purposes.

The license is subject to the CHIMIA terms and conditions: (http:// chimia.ch/component/sppagebuilder/?view=page \&id=12).

The definitive version of this article is the electronic one that can be found at https://doi.org/10.2533/chimia.2020.924 